\title{
A trajetória da educação brasileira no contexto econômico
}

\author{
The path of brazilian education in the economic context \\ La trayectoria de la educación brasileña en el contexto económico
}

\section{ANDRÉA MARIA DE MELO COUTO DE OLIVEIRA \\ PATRICIA MARIA DUSEK \\ KÁTIA ELIANE SANTOS AVELAR}

\begin{abstract}
Resumo: O estudo apresenta uma breve retrospectiva da educação brasileira, no contexto econômico, ponderando as transformações educacionais e reflexo de alguns acontecimentos históricos sobre a conjuntura atual da educação. Traçou-se um paralelo entre a (re)construção das teorias econômicas e sua (des)preocupação em superar as desigualdades. Questiona-se a aplicabilidade e consequências da Emenda Constitucional 95/2016 (teto de gastos públicos) em contraponto às demandas sociais, em especial, a educação e o cumprimento das metas estabelecidas pelo Plano Nacional de Educação (PNE) 2014-2024.
\end{abstract}

Palavras-chave: Economia, Sociedade, Desenvolvimento, Educação.

Abstract: The study presents a brief retrospective of Brazilian education in the economic context, pondering the educational transformations and reflection of some historical events on the current scenario of education. A parallel was drawn between the (re)construction of economic theories and their (un)concern in overcoming inequalities. The applicability and consequences of Constitutional Amendment 95/2016 (public spending) are questioned as a counterpoint to social demands, especially to education and the fulfillment of the goals set by the National Education Plan (PNE) 2014-2024.

Keywords: Economy, Society, Development, Education.

Resumen: El estudio presenta una breve retrospectiva de la educación brasileña, en el contexto económico, ponderando las transformaciones educativas y reflejo de algunos acontecimientos históricos sobre la coyuntura actual de la educación. Se trazó un paralelo entre la (re)construcción de las teorías económicas y su (des)preocupación en superar las desigualdades. Se cuestiona la aplicabilidad y consecuencias de la Enmienda Constitucional 95/2016 (techo de gastos públicos) en contrapunto a las demandas sociales, en especial, a la educación y el cumplimiento de las metas establecidas por el Plan Nacional de Educación (PNE) 2014-2024.

Palabras clave: Economía, Sociedad, Desarrollo, Educación. 


\section{INTRODUÇÃO}

Mediante uma revisão bibliográfica, o trabalho busca fazer a intersecção entre investimento acadêmico e a abertura do leque de possibilidades no sentido de buscar compreender a realidade educacional atual e evidenciar os desafios a serem superados, haja vista que os problemas existentes não podem ser concebidos de forma linear, mas, sim, dentro de expressões de transformações profundas, com questionamentos e reflexões contextualizados.

A relevância do trabalho recaí sobre a importância de se analisar o papel da educação no desenvolvimento socioeconômico, na construção da cidadania, no alcance dos direitos e na capacidade de se adaptar frente às mudanças. Trata de uma questão central conceber a relação tríade entre crescimento econômico, desenvolvimento e justiça social e a (re)construção da teoria econômica e sua preocupação com as desigualdades locais e regionais.

\section{BREVE RELATO HISTÓRICO}

Inicialmente, cabe fazer uma breve retrospectiva da educação brasileira no contexto econômico, ponderando sobre as transformações educacionais ao longo do tempo e indicar alguns acontecimentos históricos, seus reflexos e implicações sobre a conjuntura atual.

Optou-se por iniciar pela segunda metade do século XX, pós-guerra, por se tratar de intenso processo de modernização pelo qual passou o Brasil, com alterações estruturais relevantes em todos os setores da sociedade. No cenário mundial, o final da segunda grande guerra em 1945 e a vitória militar do grupo dos aliados geraram mudanças nas posições de liderança político-estratégica, sofrendo, muitas vezes, influência das concepções Keynesianas, isto é, ampliação de gastos públicos a fim de motivar o setor privado (MORAES et al., 2014).

Partindo desse contexto, as ações do governo brasileiro no período do presidente Juscelino Kubitschek (1956-1960), corroboraram, em parte, as concepções keynesianas, pois estavam focadas no equilíbrio entre emprego e produção e na consequente acumulação de capital. Foi um período de euforia desenvolvimentista, embalado pelo plano de metas e pelo slogan '50 anos em 5' quando o empenho era levar um rápido desenvolvimento a todo território nacional.

Os projetos desse plano de desenvolvimento foram concebidos e distribuídos em cinco grandes eixos: energia, transportes, indústria, alimentação e educação. Apesar desse grandioso apelo, algumas lacunas tornaram-se obscuras no tocante à educação, um antagonismo entre desenvolvimento e aplicação de 
investimentos, haja vista que "apenas 3,4\% das verbas foram previstas para e educação, enquanto 93\% de recursos foram destinados à energia, transporte $\mathrm{e}$ indústria de base" (STRASSBURG; OLIVEIRA; RIPPEL, 2015, p. 27).

Este baixo percentual demonstra que a educação não mereceu o mesmo tratamento que os demais setores. Não houve preocupação com a Educação Básica, sendo grande parte do investimento educacional aplicado na formação técnica e no ensino superior, embora $50,6 \%$ da população acima dos 15 anos fosse analfabeta (INEP, 2003).

A ausência de financiamento parece ter sido fator crucial para o atraso educacional. O cenário refletia um momento singular para investimentos de grande amplitude voltados para a educação básica, o que poderia ter gerado benefícios enormes para a economia brasileira ao longo prazo, uma vez que educação é uma das bases para o crescimento sustentado.

João Goulart, ao assumir a presidência em 1961, encontrou um Brasil com mais de 70 milhões de habitantes, sendo quase $40 \%$ deles, analfabetos (INEP, 2003). Esse cenário revelou também que a maioria da população "não tinha poder decisório na administração das escolas, como também não podia pleitear por expansão educacional via voto" (KANG, 2011).

Apesar de um período conturbado, marcado por instabilidade política e econômica, o governo mostrou-se preocupado com as questões sociais e educacionais. Reforçava a ideia de privilegiar o ensino primário, cabendo à União prestar auxílio financeiro aos governos em regiões com maior grau dificuldade. Parte-se então, para um discurso a favor da educação pública de qualidade, tendo em Darcy Ribeiro seu grande defensor.

Foi proposto o Plano Trienal, o aumento das despesas mínimas da União com educação de $10 \%$ para 15\% em 1964, e para 20\% em 1965. No entanto, João Goulart foi deposto em 1964 com o Golpe Militar e o Plano Trienal, não foi, de fato, posto em prática (STRASSBURG; OLIVEIRA; RIPPEL, 2015, p. 27).

A Revolução de 1964 provocou uma radical mudança política, a partir de quando o exercício do poder foi controlado, com mãos de ferro, ao longo de duas décadas. A constituição de 1967 foi aprovada e atribuiu à União competência para elaborar planos nacionais de educação e saúde. O golpe repôs a cultura do autoritarismo dentro de uma sociedade fundada no privilégio mais do que no direito e na justiça social. O Estado passou a fornecer e financiar a infraestrutura para o crescimento industrial (VIOLA; ALBUQUERQUE, 2015). 
Ainda na visão de Viola e Albuquerque (2015), pode-se dizer que durante a ditadura o país teve alguns avanços, mas muitos retrocessos com onerosos custos para os brasileiros. O governo sonegou e suprimiu direitos civis, políticos e sociais. Nos sistemas de ensino, a democracia é rompida, conteúdos são substituídos, a autonomia das universidades é reduzida e as desigualdades reforçadas.

Obviamente, a definição das políticas públicas educacionais estava voltada para os grupos que apoiaram o golpe e/ou o prosseguimento da ditadura, os quais passaram a ter um enfoque decisivo na formulação e implementação dessas políticas (CUNHA, 2014).

Essa atitude gerou pelo menos duas reflexões a serem feitas:

a) A segmentação das formulações e implementações das políticas educacionais, inclusive com direções contraditórias, modelada pelos interesses de um segmento da sociedade (VIOLA; ALBUQUERQUE, 2015);

b) A veloz expansão do ensino privado, favorecido pela legislação tributária (CUNHA, 2014, p. 363).

Entre os anos de 1968 e 1973, sob a ditadura militar, o Brasil viveu um período de extraordinária expansão econômica. Entre afirmações e controvérsias, os possíveis legados não resistiram à crise econômica dos anos seguintes.

Nas concepções de Duarte (2015, p. 78), as matrizes do milagre eram baseadas no "controle rígido do salário mínimo vigente do país e flexibilização das regras de contratação e demissão da mão de obra", gerando ao mesmo tempo, concentração de renda e empobrecimento. "A ditadura deixou para o Brasil um duplo legado de aprofundamento da desigualdade social e da degradação ambiental" (DUARTE, 2015, p. 64).

Nos anos 70, a crise mundial do petróleo elevou o preço do barril e fez a balança comercial brasileira entrar no negativo. Os sinais da desaceleração ficaram claros. A inflação disparou no final dessa década, gerando declínio no crescimento na economia mundial e consequente, degradação do controle dos Estados Nacionais. De acordo com Singer (2012), os choques do petróleo criaram um desequilíbrio nas contas externas e os déficits progressivos foram cobertos por um crescente fluxo de empréstimos externos (petrodólares) feitos por bancos privados.

A partir de então, começou a disseminação da teoria monetarista neoliberal que previa a descentralização do Estado e a redução do investimento em setores sociais. Estavam em xeque, modelos de desenvolvimento apoiados em altas doses de endividamento externo. A democracia neoliberal era meramente um mecanismo "para escolher e autorizar governos, e não uma espécie de sociedade, nem um conjunto de fins morais" (BENDRATH; GOMES, 2011 p. 97). 
Os anos 80 foram marcados por profunda crise econômica e pelo fim da ditadura (1964-1985), acompanhado por movimentos de redemocratização em todos os campos sociais, inclusive na educação. A volta da democracia possibilitou uma reorganização do movimento social; no contexto econômico, porém, o Brasil ainda estava submisso às exigências contratuais do Banco Mundial e do FMI, num modelo de desenvolvimento, baseado em investimento estatal e financiamento externo, que influenciou profundamente as políticas internas dos países devedores.

O Brasil viveu anos de instabilidade monetária e cambial. Aumentava a concentração de renda e riqueza e, consequentemente, acentuavam-se as desigualdades sociais. Então, o país centrava sua agenda governamental no controle da inflação e na retomada do crescimento econômico. Corroborando essa premissa, Pereira (2013) salientou que o programa de ajustamento do Banco Mundial consistia, em linhas gerais, na mesma agenda monetarista aplicada pelo FMI desde a década de 1960.

Diante desse difícil cenário e com o fim da ditadura militar, vários aspectos da política nacional necessitavam ser repensados, entre os quais centravam-se a Educação e a elaboração da Constituição de 1988 que, em seu artigo 212, determinava índices específicos para aplicabilidade na área educacional: mínimo de $18 \%$ da receita dos impostos pela União e $25 \%$ pelos estados e municípios (BRASIL, 1988).

Paralelamente, no contexto mundial, a reestruturação capitalista neoliberal, recomendou novas diretrizes, objetivando o ajustamento das economias periféricas. A agenda de reformas conhecida como o Consenso de Washington foi publicada em 1990 e, no caso do Brasil, trouxe dez estratégias a serem seguidas, como a rápida privatização, flexibilização de direitos trabalhistas e redução de investimentos em políticas públicas básicas (LEME, 2010).

Esse receituário procurou minimizar o processo inflacionário, aumentando as restrições ao crédito, o arrocho salarial e os gastos públicos. Tais delineamentos de política acentuaram, nos anos 90, os efeitos negativos para os assalariados, evidenciando a concentração de renda e as desigualdades.

De acordo com Leme (2010), os problemas relativos às políticas sociais não foram tratados como prioritários, gerando entraves em áreas como, educação, saúde, cultura, eliminação da pobreza e distribuição de renda, pois essas áreas eram tratadas, basicamente, com políticas compensatórias. 


\section{A ESCOLA DO SÉCULO XXI: NEOLIBERALISMO E GLOBALIZAÇÃO}

Ao refletir sobre a educação contemporânea, nota-se que "ideologia econômica neoliberal, no processo educacional, introduziu um período de degradação em relação ao investimento e ao reconhecimento social da área" (SANTOS MELO; LUCEMI, 2012, p. 4363).

Apesar de sua inegável importância, a educação pública há muito tempo vem sofrendo cortes orçamentários que colaboram para a evasão e a má formação. A economia, sem trabalhadores qualificados, não conseguirá adaptar-se ou dar suporte a processos de produção mais sofisticados tecnologicamente nem proporcionar desenvolvimento econômico (ARBIX; LINS, 2011).

A educação continua sendo vista de forma secundária pelos governantes. Cabe ressaltar a importância do acatamento à meta 20 do Plano Nacional de Educação (PNE 2014-2024), que estipula ampliar o investimento em educação pública até atingir 10\% do PIB ao final do decênio. Essa meta já havia sido apontada no PNE anterior e não alcançada (BRASIL, 2014).

Segundo dados do relatório da Organização de Cooperação e de Desenvolvimento Econômico (OCDE, 2015), o gasto público brasileiro em instituições da Educação Básica à Educação Superior representou 5,6\% do PIB, em 2012. Considerando apenas o investimento público em educação, o Brasil investe anualmente cerca de 3.000 dólares por aluno da Educação Básica. Esse valor, que se refere a 2012 , é $110 \%$ maior do que o investimento médio por aluno registrado em 2005. No entanto, ainda está abaixo da média da OCDE, que investe mais de 8.200 dólares por aluno.

Apesar de o aporte financeiro ter aumentado, os resultados de aprendizagem continuam ruins. $\mathrm{O}$ Brasil precisa investir mais e melhor. $\mathrm{O}$ recurso disponibilizado para a escola não resolverá todos os problemas, mas, certamente, será elemento fundamental para o crescimento e qualidade da educação formal. Torna-se injusto "conferir aos educadores e alunos, a culpa pela degradação educacional, é jogar a culpa em quem não é culpado" (SANTOS; MELO; LUCEMI, 2012 p. 4363).

O PNE (período 2014-2024) reconhece a dimensão e a importância dessa meta, ao ressaltar que, a partir dela, o alcance das outras metas poderá ser facilitado, isto é, perspectivas reais de avanço para a educação pública, "nas dimensões da universalização e ampliação do acesso, qualidade e equidade" (BRASIL, 2014, p. 23). 
Diante do exposto, aposta-se na educação como suporte para o desenvolvimento ideal e sustentado, mas, para isso, os estudos devem estar focados em discutir, analisar e propor novas ações e atitudes, gerando embasamento e confiança na implantação de decisões autônomas e realistas.

Apesar de sua inegável importância, a educação ainda vem sendo tratada como fator secundário; basta atentar para a aprovação da Proposta da Ementa Constitucional (PEC) 241 que limitou os gastos públicos, pelos próximos 20 anos. Promulgada em dezembro de 2016, como Emenda Constitucional 95, passou a configurar-se como lei. Pela medida, os gastos públicos totais serão reajustados com base na inflação oficial do ano anterior (BRASIL, 2016). Tal medida impedirá investimentos, sobretudo, nas áreas sociais, agravando a recessão e prejudicando os mais pobres.

Ao analisar a estrutura capitalista e a ótica liberal dessa lei, nota-se que a "definição de políticas públicas em geral e do financiamento da educação em particular está sujeita à estrutura da sociedade em termos ideológico-econômicos" (AMARAL, 2017, p. 3).

Nesse sentido, as despesas primárias do MEC somente poderão crescer caso haja uma diminuição equivalente em outro setor do Executivo. Pode-se prever que o MEC dificilmente conseguirá trazer, nesses longos 20 anos, recursos maiores que a inflação medida pelo IPCA (Índice de Preços ao Consumidor Ampliado) do ano anterior.

Cabe salientar que esses 20 anos, que se estenderão até 2036, abrangerão o período do Plano Nacional de Educação (PNE), aprovado pela Lei no 13.005 de 25 de junho de 2014, o PNE 2014-2024, cujas metas dificilmente serão atingidas, apesar de representarem um compromisso assumido com a garantia do direito à educação pelo Estado.

Em contrapartida, não há um patamar limítrofe para as despesas relacionadas à dívida pública. A evolução de pagamento de JEAD (simplificação da expressão 'juros, encargos e amortização das dívidas internas e externas'), no período de 1998-2015 foi muito superior à evolução das despesas primárias (AMARAL, 2016).

Isso, em 2016, em um país onde $25,4 \%$ da população vive em situação de pobreza. A situação é mais grave entre os 7,4 milhões de moradores de domicílios onde vivem mulheres pretas ou pardas sem cônjuge com filhos até 14 anos (IBGE, 2017).

Pelo exposto, O Novo Regime Fiscal (NRF) atua, portanto, na contramão da continuidade do enfretamento dos níveis de desigualdade social, maior concentração de renda e, consequentemente, num recrudescimento da vida daqueles que são mais vulneráveis. 
A configuração da PEC parece ancorar-se em uma concepção de progresso que desconsidera o papel proeminente dos investimentos públicos em educação, saúde, assistência social e cultura no desenvolvimento. Desse modo, a PEC parece passar ao largo da perspectiva de despesas sociais como um investimento capaz de dinamizar a economia e seu próprio financiamento (PAIVA.; MESQUITA; JACCOUD; PASSOS, 2016).

Assim, aumentos na arrecadação não poderão ser revertidos na implantação ou no aperfeiçoamento de políticas públicas. Nem, tampouco, transferir-se a novas demandas sociais impactadas pelo aumento populacional.

\section{CONSIDERAÇÕES FINAIS}

O crescimento econômico é fundamental; "não pode ser considerado um fim em si mesmo", porém. (SEN, 2010, p.29). O desenvolvimento deve estar relacionado à melhora das condições de vida dos indivíduos e o fortalecimento de suas potencialidades, como fatores propulsores da liberdade. Assim, o autor fez o seguinte enfoque, ao suscitar: (a) considerando a educação como um fim em si mesma; (b) considerando a educação como meio a partir do qual se podem atingir fins mais elevados.

No entanto, o poder público continua negligenciando metas e políticas educacionais. Um exemplo é o novo regime fiscal, sob o prisma da Ementa Constitucional 95/2016 (teto dos gastos públicos), uma forma revestida do neoliberalismo, que acompanha a dinâmica brasileira por muito tempo, ou seja, o Estado procurando atender os próprios interesses internos sob o olhar atento da burguesia nacional (OKUMURA, 2018).

O novo governo assume a presidência brasileira em 2019 e encontra um orçamento definido e aprovado. Independentemente de suas propostas ou prioridades, somente poderá efetivar novo orçamento em 2020, já transcorridos seis anos do PNE 2014-2024. Nesse sentido, fica o questionamento quanto à possibilidade ou viabilidade do acatamento de metas, em apenas quatro anos restantes (AMARAL, 2017).

Essa racionalidade perversa desconsidera que investimentos em educação devem ser transformados em conquistas concretas para as pessoas (SEN, 2010). Apesar de, paulatinamente, o discurso girar em prol da universalização da educação pública e ensino de qualidade. Esse cenário ainda não faz parte da realidade de muitos, considerando-se que o pobre ainda sofre com um sucateamento estrutural das escolas e ações pedagógicas ineficientes, transformando-se em caricatura de inclusão social (LIBÂNEO, 2012). 
Os orçamentos associados à área social (educação, saúde, combate à fome etc.) se reduzem; em contraponto, ampliam-se os recursos para pagamento de juros e amortização da dívida. Essa metodologia empregada provoca severa ameaça à garantia do direito à educação com equidade e qualidade, criando um imenso retrocesso na pirâmide social brasileira.

Ainda sobre os possíveis malefícios da adoção de uma política de ajuste fiscal tão restritiva, cabe indagar sobre diversas situações de violação de direitos, isto é, fatores impeditivos para a adoção de políticas públicas, em especial para a população pobre e vulnerável.

Diante do exposto e em consonância ao atual cenário brasileiro, cabe refletir se o caminho adotado para o crescimento econômico é o mais viável e justo.

\section{REFERENNCIAS}

AMARAL, N. C. PEC 241/55: a "morte" do PNE (2014-2024) e o poder de diminuição dos recursos educacionais. Revista Brasileira de Política e Administração da Educação, set./dez, v. 32, nº 3, p. 653-673, 2016.

AMARAL, N. C. Com a PEC 241/55 (EC 95) haverá prioridade para cumprir as metas do PNE (2014-2024)? Revista Brasileira de Educação, Goiânia, set./ dez, v. 22, no 71, p. 1-25, 2017.

ARBIX, G; LINS, L. M. Educação, qualificação, produtividade e crescimento econômico: a harmonia colocada em questão. In: Circuito e Debates Acadêmicos, Anais... São Paulo: IPEA, 2011.

BECKER, K. L.; KASSOUF, A. L. Uma análise do efeito dos gastos públicos em educação sobre a criminalidade no Brasil. Economia e Sociedade: Campinas, v. 26, no 1(59), p. 215-242, 2017.

BENDRATH. E. A.; GOMES, A. A. Educação e economia: a (re) construção histórica a partir do pós-guerra. Campinas: Revista HISTEDB, On-line, Campinas, no 44, p. 92-106. 2011. Disponível em: http:/ / www.histedbr.fe.unicamp. br/revista/edicoes/44/art07_44.pdf. Acesso em: 17 set. 2018.

BRASIL. Emenda Constitucional 95 de 15 de dezembro de 2016. Altera o Ato das Disposições Constitucionais Transitórias, para instituir o Novo Regime Fiscal. Brasília: Câmara dos Deputados. 2016. 
Lei $\mathrm{n}^{\mathbf{0}} \mathbf{1 3 . 0 0 5}$ de 15 de junho de 2014. Aprova o Plano Nacional de Educação (PNE) 2014-2024. Brasília: Câmara dos Deputados. 2014.

Constituição de 5 de outubro de 1988. Constituição: República Federativa do Brasil. Brasília: Senado Federal, 1988.

BRESSER-PEREIRA, L. C. O conceito histórico de desenvolvimento econômico. São Paulo: EESP/FGV, dez. 2006. Versão 2008.

CUNHA, L. A. O legado da ditadura para a educação brasileira. Cedes: Campinas: Unicamp, v. 35, nº 127, p. 357-377, 2014.

DUARTE, R. H. Poluição atmosférica e modelo de desenvolvimento no "milagre" brasileiro (1967-1973). Rio de Janeiro: Revista Tempo, v. 21, no 37, p. 64-87, 2015.

IBGE - Instituto Brasileiro e Geografia e Estatística. Um quarto da população vive com menos de R $\$ 387$ por mês. Rio de Janeiro: Ed. Estatísticas Sociais, 2017. Disponível em: <https://agenciadenoticias.ibge.gov.br/agencia-noticias/2012agencia-de-noticias/ noticias/18825-um-quarto-da-populacao-vive-com-menosde-r-387-por-mes>. Acesso em: 18 set. 2018.

. Síntese de indicadores sociais 2013: uma análise das condições de vida da população brasileira. Rio de Janeiro: IBGE, 2013.

INEP - Instituto Nacional de Estudos e Pesquisas Educacionais Anísio Teixeira. O mapa do Analfabetismo no Brasil. Brasília: INEP. 2003. Disponível em: <http://portal.inep.gov.br/documents/186968/485745/ $\mathrm{Mapa}+\mathrm{do}+$ analfabetismo + no + Brasil/a 53 ac9ee-c0c0-4727-b216035c65c45e1b?version=1.3>. Acesso em: 06 jun. 2017

KANG, T. Descentralização e financiamento da educação brasileira: uma análise comparativa,1930-1964. Revista Estudos Econômicos, v. 41, nº 3, jul-set, p. 573-598, 2011.

LEME, A. A. Neoliberalismo, globalização e reformas do estado: reflexões acerca da temática. Barbarói. Santa Cruz do Sul, nº 32, jan./jul, p. 114-138, 2010. 
MORAES, A. C. et al. O capital financeiro: da gênese à crise contemporânea. Pesquisa \& Debate, SP, v. 25, no 2(46), p. 69-89, jul-dez. 2014.

MORIN, E. Os sete saberes necessários à educação do futuro. São Paulo: Cortez, 2011

OCDE - Organização de cooperação e de desenvolvimento econômico. Brasil em Education at a Glance 2015: Indicadores da OCDE, 2015. Disponível em: <2015 https://www.oecd.org/brazil/Education-at-a-glance-2015-Brazil-inPortuguese.pdf $>$. Acesso em: 24 mai. 2017.

OKUMURA, J. H. Democracia e Educação: Florestan Fernandes em Defesa da Escola Pública. Salvador: Germinal: Marxismo e Educação em Debate, 2018.

PAIVA, A. B.; MESQUITA, A. C. S.; JACCOUD, L.; PASSOS, L. O Novo Regime Fiscal e suas implicações para a política de assistência social no Brasil (Nota Técnica). Brasília: IPEA, 2016. Disponível em: < http://www.ipea. gov.br/portal/images/stories/PDFs/nota_/160920_nt_27_disoc.pdf $>$. Acesso em: 16 set. 2018.

PEREIRA, J. M. M. O Banco Mundial e a construção política dos programas de ajustamento estrutural nos anos 1980. São Paulo: ANPUH, 2013.

SANTOS, J. D.; MELO, A. K. D.; LUCEMI, M. Uma breve reflexão retrospectiva da educação brasileira (1960-2000): implicações contemporâneas. X Seminário Nacional de Estudos e Pesquisas História, Sociedade e Educação no Brasil. João Pessoa: UFP, 2012.

SEN, A. Desenvolvimento como liberdade. São Paulo: Companhia das Letras, 2010.

SILVEIRA, G. F.; GOMES, M. M.; LIMA, J. E.; SILVA, J. M. A. Retornos da escolaridade no Brasil e regiões. São Caetano do Sul: Revista Gestão e Regionalidade, v. 31, $\mathrm{n}^{\circ}$ 91, p. 17-32, 2015.

SINGER, P. Globalização e desemprego: diagnóstico e alternativas. São Paulo: Contexto, 2012, p.139 
STRASSBURG, U; OLIVEIRA, N. M.; RIPPEL, R. Planejamento da educação brasileira: uma ferramenta para o desenvolvimento. Revista Orbis Latina, v. 5, $\mathrm{n}^{\circ}$ 1, jan-dez, p. 19-37, 2015.

TROMBETTA, S. Educação e Sustentabilidade. REVISEA: Revista Sergipana de Educação Ambiental, São Cristóvão, v. 1, no 1, p. 24-40, 2014.

VIOLA, S. E. A.; ALBUQUERQUE, P. P. Ditadura e educação: conexões a serem ressignificadas. Revista Reflexão e Ação, Santa Cruz do Sul, v. 23, nª 2, p.78-96, jul./out, 2015. Disponível em: https://online.unisc.br/seer/index.php/reflex/ article/viewFile/6224/pdf_25. Acesso em: 24 jun. 2017.

ZANIRATO, S. H.: ROTONDARO, T. Consumo, um dos dilemas da sustentabilidade. Estudos Avançados, v. 30, nº 88, p. 77-92, 2016. Disponível em: $\quad<$ http://www.scielo.br/pdf/ea/v30n88/0103-4014-ea-30-88-0077.pdf>. Acesso em: 17 set. 2018.

ANDRÉA MARIA DE MELO COUTO DE OLIVEIRA é Graduada em Matemática. Mestre pelo Programa de Pós-graduação em Desenvolvimento Local do Centro Universitário Augusto Motta, UNISUAM. E-mail: andrea@macae.ufrj.br

PATRICIA MARIA DUSEK é Pós-doutora em Justiça Constitucional pela Università di Pisa. Coordenadora e Pesquisadora do Programa de Pósgraduação em Desenvolvimento Local do Centro UNISUAM. E-mail: patricia.dusek@unisuam.edu.br

ORCID: https://orcid.org/0000-0003-3911-6943

KÁtIA ELIANE SANTOS AVELAR é Doutora em Ciências. Docente e Pesquisadora do Mestrado em Desenvolvimento Local do Centro Universitário Augusto Motta, UNISUAM. Rio de Janeiro/RJ. E-mail: katia.avelar@gmail.com

ORCID: https://orcid.org/0000-0002-7883-9442 